\title{
Piezoelectric Detection and Response Characteristics of Barium Titanate Unimorph Cantilevers Under AC Electric Fields
}

\section{Fumio Narita* and Yasuhide Shindo}

Department of Materials Processing, Graduate School of Engineering, Tohoku University, Aoba-yama 6-6-02, Sendai 980-8579, Japan

\begin{abstract}
This paper studies the detection and response characteristics of barium titanate (BT) unimorph cantilevers under alternating current (AC) electric fields both numerically and experimentally. The unimorph cantilever consists of the BT layer and $\mathrm{Cu}$ shim, and the BT layer has sensing, grounding and driving electrodes. The deflection and output voltage of the cantilevers were predicted by three dimensional finite element analysis (FEA). The deflection and output voltage were also measured, and a comparison was made between prediction and experiment. The deflection, stress, output voltage and output power were then discussed.
\end{abstract}

Publication History:

Received: March 11, 2014

Accepted: April 18, 2015

Published: April 20, 2015

\section{Keywords:}

Analysis and test, Dynamic bending, Lead-free ferroelectric ceramics, Piezomechanics, Selfpowering and sensing

\section{Introduction}

Piezoelectric ceramics, polymers and composites are widely used in sensors and actuators in the field of smart materials and structures [13]. With an increasing concern about global warming, the direction of research has changed slightly from just sensors and actuators to an interest in extracting and storing energy from the environment $[4,5]$. Some investigations have also focused on the design of self-powering, self-sensing and self-controlling devices. Recently, Wang and Inman [6] examined the concept and design of a multifunctional composite sandwich structure for simultaneous energy harvesting and vibration control. They proposed the glass fiber reinforced composite materials with lead zirconate titanate (PZT) harvester, PZT sensor and PZT actuator, and studied the configurations, locations and operating modes of PZT materials for optimal power generation.

Lead oxide-based ferroelectrics, especially PZT, exhibit high piezoelectric properties. Due to lead toxicity, however, the introduction of legislation in Europe to limit the usage of lead in automotive and electronic products has led to a worldwide search for lead-free compounds [7]. $\mathrm{BT}\left(\mathrm{BaTiO}_{3}\right)$ is one of the most widely investigated lead-free ceramics. Recently, BT-based piezoelectric ceramics have been prepared, and compared with commercial hard PZT materials [8]. Although many researchers are developing the multifunctional composites using PZT materials, few of the BT-based multifunctional composites have been investigated.

In this paper, we discuss the detection and response characteristics of BT unimorph cantilevers with sensing, grounding and driving electrodes under AC electric fields. A three-dimensional FEA was performed to predict the deflection and output voltage in the BT unimorph cantilevers. The deflection and output voltage were also measured, and numerical results were compared with measured values. The deflection, stress, output voltage and output power were then examined in detail.

\section{Analysis}

\section{Basic equations}

Equations of motion and Gauss' law are given by

$$
\sigma_{j i, j}=\rho u_{i, t t}
$$

$$
D_{i, i}=0
$$

where $\sigma_{i j}$ is the stress tensor, $u_{i}$ is the displacement vector, $\rho$ is the mass density, $D$ is the electric displacement vector, and a comma denotes partial differentiation with respect to the coordinates $x_{i}(i$ $=1,2,3)$ or the time $t$. We have employed Cartesian tensor notation and the summation convention for repeated tensor indices. Constitutive relations can be written as

$$
\begin{aligned}
& \varepsilon_{i j}=s_{i j k l} \sigma_{k l}+d_{k i j} E_{k} \\
& D_{i}=d_{i k l} \sigma_{k l}+\varepsilon_{i k}^{T} E_{k}
\end{aligned}
$$

where $\varepsilon_{i j}$ is the strain tensor, $E_{i}$ is the electric field intensity vector, and $s_{i j k l}, d_{k i j}$ and $\varepsilon_{i k}^{T}$ are the elastic compliance, direct piezoelectric coefficient and permittivity at constant stress, which satisfy the following symmetry relations:

$$
S_{i j k l}=S_{j i k l}=S_{i j l k}=S_{k l i j}, d_{k i j}=d_{k j i}, \varepsilon_{i j}^{T}=\varepsilon_{j i}^{T}
$$

The relation between the strain tensor and the displacement vector is given by

$$
\varepsilon_{i j}=\frac{1}{2}\left(u_{j, i}+u_{i, j}\right)
$$

and the electric field intensity vector is

$$
E_{i}=-\phi_{, i}
$$

where $\phi$ is the electric potential. The constitutive relations (3) and (4) for piezoelectric ceramics poled in the $x_{3}$-direction are given in Appendix A.

\section{Finite element method}

A unimorph cantilever constructed of BT layer and $\mathrm{Cu}$ shim is shown in Figure 1a. Let the coordinate axes $x=x_{1}$ and $\mathrm{y}=x_{2}$ be chosen such that they coincide with the interface and the $\mathrm{z}=x_{3}$ axis is perpendicular to this plane. The origin of the coordinate system is

"Corresponding Author: Dr. Fumio Narita, Department of Materials Processing, Graduate School of Engineering, Tohoku University, Aoba-yama 6-6-02, Sendai 980-8579, Japan; E-mail: narita@material.tohoku.ac.jp

Citation: Narita F, Shindo Y (2015) Piezoelectric Detection and Response Characteristics of Barium Titanate Unimorph Cantilevers Under AC Electric Fields. Int J Metall Mater Eng 1: 103. doi: http://dx.doi.org/10.15344/24552372/2015/103

Copyright: (c) 2015 Narita et al. This is an open-access article distributed under the terms of the Creative Commons Attribution License, which permits unrestricted use, distribution, and reproduction in any medium, provided the original author and source are credited. 
Citation: Narita F, Shindo Y (2015) Piezoelectric Detection and Response Characteristics of Barium Titanate Unimorph Cantilevers Under AC Electric Fields. Int J Metall Mater Eng 1: 103. doi: http://dx.doi.org/10.15344/2455-2372/2015/103

Page 2 of 4

located at the center of the bottom left side of BT layer, and the edge at $x=0$ is clamped. The geometry and dimension are shown in Figure 1b. BT layer of length $50 \mathrm{~mm}$, width $25 \mathrm{~mm}$ and thickness $1 \mathrm{~mm}$ is added to the upper surface of $\mathrm{Cu}$ shim of length $50 \mathrm{~mm}$, width $25 \mathrm{~mm}$ and thickness $0.5 \mathrm{~mm}$. The total thickness is $1.5 \mathrm{~mm}$.

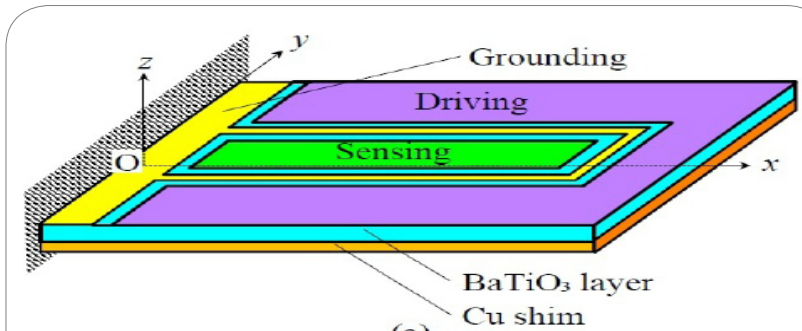

(a)
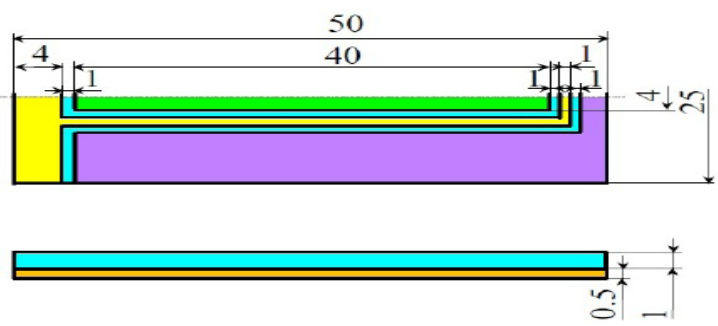

(b)

unit: $\mathrm{mm}$

Figure 1: Schematic drawing of (a) BT unimorph cantilever and (b) geometry and dimensions.

BT layer has sensing, grounding and driving electrodes. The sensing and driving electrodes are located at the center and outer parts, respectively. To suppress coupling, there is a grounding electrode between these two electrodes [9]. On the other hand, only a whole grounding electrode is located on the opposite side.

We performed three-dimensional finite element calculations. The commercial software ANSYS with 3D eight-node elements was used in the analysis. For simplicity, the electrode layers were not incorporated into the model. This is because the thickness of the electrode layer is much smaller than the thickness of the BT layer. The electric potential on the top driving electrode surface equals the applied voltage $\phi=$ $V_{0} \exp (\mathrm{i} \omega \mathrm{t})$, where $V_{0}$ is the amplitude of applied voltage and $\omega$ is angular frequency. The top and bottom grounding electrode surfaces are connected to the ground, so that $\phi=0$. The deflection and internal stress for the cantilever were then calculated. The output voltage of sensing electrode was also predicted.

\section{Experimental Procedure}

The unimorph cantilever was fabricated using BT layer (NEC/Tokin Co. Ltd., Japan) and $\mathrm{Cu}$ substrate. Table 1 lists the material properties of BT layer. Elastic compliances $s_{11}, s_{33}$, direct piezoelectric coefficients $d_{31} d_{33}$, dielectric permittivity $\epsilon_{33}^{\mathrm{T}}$ and mass density $\rho$ can be found in the published data, while the remaining properties are assumed to be the same as those of BT reported by Jaffe and Berlincourt [10]. The elastic compliance (inverse of Young's modulus), Poisson's ratio and mass density of $\mathrm{Cu}$ shim are $7.69 \times 10^{-12} \mathrm{~m}^{2} / \mathrm{N}, 0.34$ and $8920 \mathrm{~kg} / \mathrm{m}^{3}$, respectively. Electrodes were coated on both sides of BT layer, and the BT layer was bonded to the upper surface of $\mathrm{Cu}$ shim by conductive bonding, as shown in Figure 1. A resistive load was then connected to the cantilever.

An AC voltage was applied to the driving electrode surface of the BT layer, while the grounding electrode surfaces were earthed. The amplitude of tip deflection $w_{\text {tip }}$ of the cantilever was measured with a laser displacement sensor (LK-G10, KEYENCE, Co. Ltd., Japan). Output peak voltage $V_{\text {out }}$ of the sensing electrode was also measured for the cantilever using an oscilloscope (GDS-1062A, Good Will Instrument Co., Ltd., Japan). Then, the output power $P_{\text {out }}$ from the cantilever can be calculated using the output peak voltage $V_{\text {out }}$ and load resistance $R$.

\section{Results and Discussion}

Figure 2 shows the amplitude of the tip deflection amplitude $\left|\mathrm{w}_{\text {tip }}\right|$ as a function of $\mathrm{AC}$ electric field amplitude $E_{0}$ for BT unimorph cantilever without load resistance at frequency $f=\omega / 2=50 \mathrm{~Hz}$. The solid line represents the value of the tip deflection predicted by the FEA, and the solid circle denotes the measured data. For comparison, the predicted deflection for PZT C-203 unimorph cantilever (Fuji Ceramics Co. Ltd., Japan) is also shown as dashed line. The material properties of C-203 are listed in Table 2, and the coercive electric field is about $2 \mathrm{MV} / \mathrm{m}$. Note that the tip deflection for PZT C-203 unimorph cantilever was predicted considering domain wall motion [11]. A nonlinear relationship between the tip deflection and electric field is observed for PZT C-203 cantilever. On the other hand, the tip

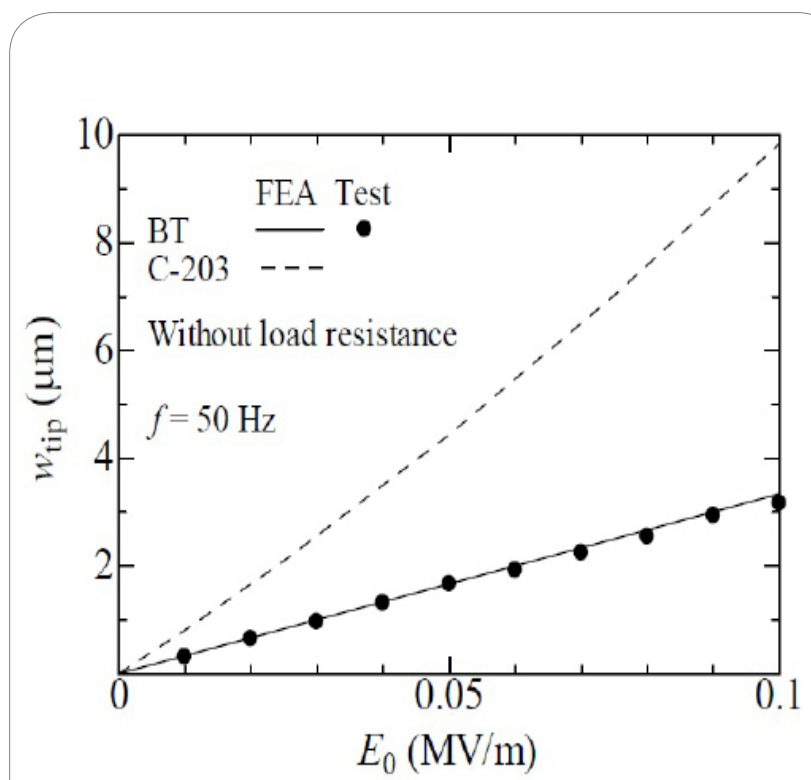

Figure 2: Tip deflection amplitude versus electric field amplitude.

\begin{tabular}{|c|c|c|c|c|c|c|c|c|c|c|}
\hline \multicolumn{5}{|c|}{$\begin{array}{l}\text { Elastic compliance } \\
\left(\times 10^{-12} \mathrm{~m}^{2} / \mathrm{N}\right)\end{array}$} & \multicolumn{3}{|c|}{$\begin{array}{l}\text { Direct piezoelectric coefficient } \\
\qquad\left(\times 10^{-12} \mathrm{~m} / \mathrm{V}\right)\end{array}$} & \multicolumn{2}{|c|}{$\begin{array}{c}\text { Dielectric } \\
\text { permittivity } \\
\left(\times 10^{-10} \mathrm{C} / \mathrm{Vm}\right)\end{array}$} & \multirow{2}{*}{$\begin{array}{l}\begin{array}{c}\text { Mass } \\
\text { density } \\
\left(\mathrm{kg} / \mathrm{m}^{3}\right)\end{array} \\
\rho\end{array}$} \\
\hline$s_{11}$ & $s_{33}$ & $s_{44}$ & $s_{12}$ & $s_{13}$ & $d_{31}$ & $d_{33}$ & $d_{15}$ & $\varepsilon_{11}^{\mathrm{T}}$ & $\varepsilon_{33}^{\mathrm{T}}$ & \\
\hline $8.85^{\mathrm{a}}$ & $8.95^{\mathrm{a}}$ & 22.8 & -2.7 & -2.9 & $-60^{a}$ & $140^{\mathrm{a}}$ & 260 & 128 & $102^{\mathrm{a}}$ & $5400^{\mathrm{a}}$ \\
\hline
\end{tabular}

Table 1: Material properties of BT.

${ }^{a} \mathrm{NEC} /$ Tokin's product data sheets 
Citation: Narita F, Shindo Y (2015) Piezoelectric Detection and Response Characteristics of Barium Titanate Unimorph Cantilevers Under AC Electric Fields. Int J Metall Mater Eng 1: 103. doi: http://dx.doi.org/10.15344/2455-2372/2015/103

Page 3 of 4

\begin{tabular}{|c|c|c|c|c|c|c|c|c|c|c|}
\hline \multicolumn{5}{|c|}{$\begin{array}{l}\text { Elastic compliance } \\
\left(\times 10^{-12} \mathrm{~m}^{2} / \mathrm{N}\right)\end{array}$} & \multicolumn{3}{|c|}{$\begin{array}{l}\text { Direct piezoelectric coefficient } \\
\qquad\left(\times 10^{-12} \mathrm{~m} / \mathrm{V}\right)\end{array}$} & \multicolumn{2}{|c|}{$\begin{array}{c}\text { Dielectric } \\
\text { permittivity } \\
\left(\times 10^{-10} \mathrm{C} / \mathrm{Vm}\right)\end{array}$} & \multirow{2}{*}{$\begin{array}{r}\begin{array}{r}\text { Mass } \\
\text { density } \\
\left(\mathrm{kg} / \mathrm{m}^{3}\right.\end{array} \\
\rho\end{array}$} \\
\hline$s_{11}$ & $s_{33}$ & $s_{44}$ & $s_{12}$ & $s_{13}$ & $d_{31}$ & $d_{33}$ & $d_{15}$ & $\varepsilon_{11}^{\mathrm{T}}$ & $\varepsilon_{33}^{\mathrm{T}}$ & \\
\hline 13.9 & 16.7 & 42.7 & -4.1 & -6.4 & -144 & 325 & 522 & 131 & 129 & 7700 \\
\hline
\end{tabular}

Table 2: Material properties of C-203.

deflection for BT unimorph cantilever increases linearly as the electric field increases, and the results of the FEA are in excellent agreement with measured data. It is therefore expected that the domain wall motion may not occur in the BT layer under AC electric fields. The formation of defect complexes during manufacturing of the BT layer are thought to reduce the mobility of ferroelectric domain wall. Figure 3 shows the predicted and measured output peak voltage $V_{\text {out }}$ of the sensing electrode as a function of $\mathrm{E}_{0}$ for $\mathrm{BT}$ unimorph cantilever without load resistance at $f=50 \mathrm{~Hz}$. Also shown is the predicted data for PZT C-203 unimorph cantilever. The output peak voltage for BT unimorph cantilever increases linearly as the electric field increases, similar to the tip deflection. It can be seen that agreement between FEA and test is fair. The results show that the output voltage is capable of self-powering or self-sensing.

The variation of normal stress amplitude $\left|\sigma_{x x}\right|$ along the length direction is calculated for BT unimorph cantilever without load resistance at a chosen point ( $y=0 \mathrm{~mm}$ and $z=1 \mathrm{~mm}$ here) and the result is shown in Figure 4. All calculations were done for $E_{0}=0.1$ $\mathrm{MV} / \mathrm{m}$ at $f=50 \mathrm{~Hz}$. The output peak voltage of the cantilever under $E_{0}=0.1 \mathrm{MV} / \mathrm{m}$ at $f=50 \mathrm{~Hz}$ is about $V_{\text {out }}=2.0 \mathrm{~V}$. A high normal stress occurs near the center of the BT unimorph cantilever. Figure 5 shows the variation of normal stress amplitude $\left|\sigma_{x x}\right|$ along the width direction for BT unimorph cantilever without load resistance at $x=$ $25 \mathrm{~mm}$ and $z=1 \mathrm{~mm}$. All calculation was done for $\mathrm{E}_{0}=0.1 \mathrm{MV} / \mathrm{m}$ at $f=50 \mathrm{~Hz}$. There is a substantial difference in the stress near the edge of driving electrode. It is noted that the normal stress for the sensing part is much higher than that for the driving part. The results for the evaluation of stresses may help multielectroded BT cantilever designers to estimate the fracture risk and to optimize in-service loading conditions.

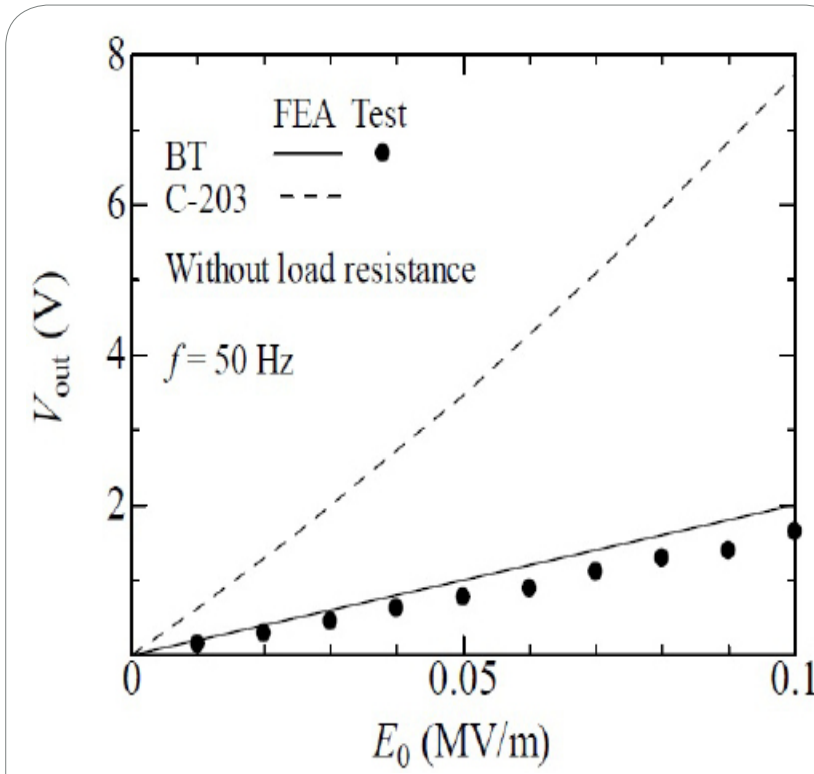

Figure 3: Output peak voltage versus electric field amplitude.

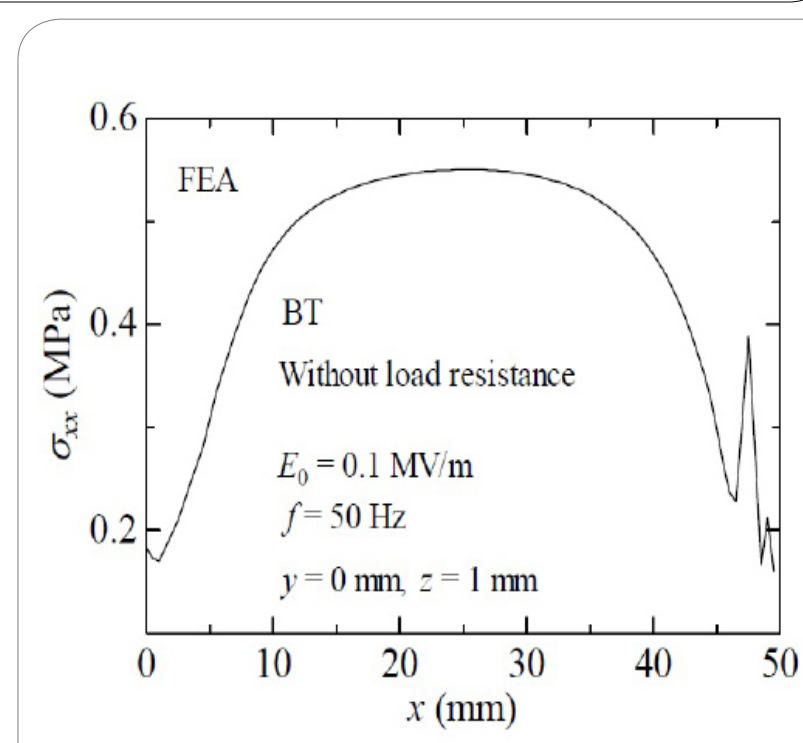

Figure 4: Distribution of normal stress amplitude along the length direction.

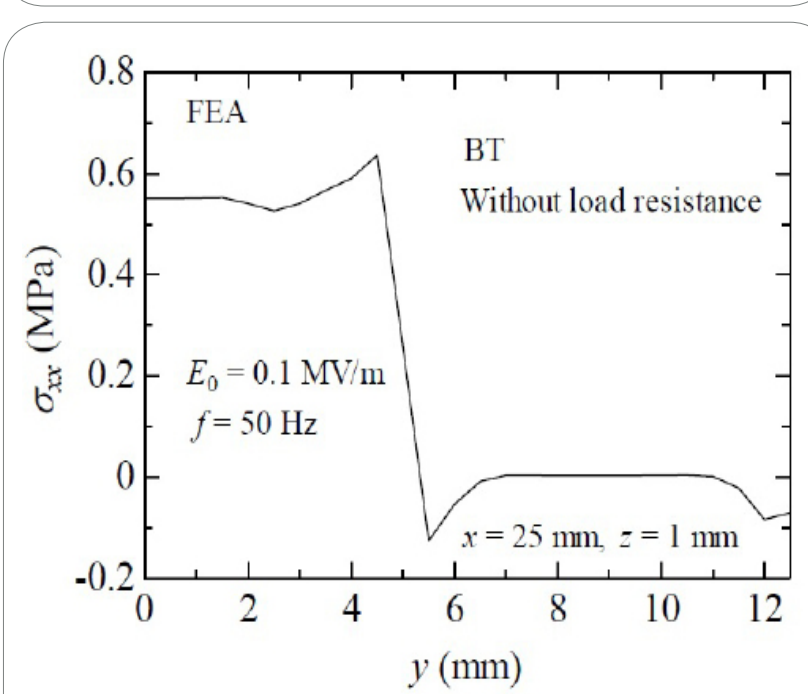

Figure 5: Distribution of normal stress amplitude along the width direction.

The variation of the measured output peak voltage $V_{\text {out }}$ of the sensing electrode with changing load resistance $R$ is shown in Figure 6 for BT unimorph cantilever under $E_{0}=0.1 \mathrm{MV} / \mathrm{m}$ at $f=50 \mathrm{~Hz}$. The output voltage increases with load resistance. Figure 7 shows the output power $P_{\text {out }}$ for BT unimorph cantilever under $E_{0}=0.1 \mathrm{MV} / \mathrm{m}$ at $f=50 \mathrm{~Hz}$. The output power tends to increase with load resistance reaching a peak and then to decrease in magnitude. It can be seen that the optimal load resistance for BT unimorph cantilever is about $2 \mathrm{M} \Omega$. 
Citation: Narita F, Shindo Y (2015) Piezoelectric Detection and Response Characteristics of Barium Titanate Unimorph Cantilevers Under AC Electric Fields. Int J Metall Mater Eng 1: 103. doi: http://dx.doi.org/10.15344/2455-2372/2015/103

Page 4 of 4

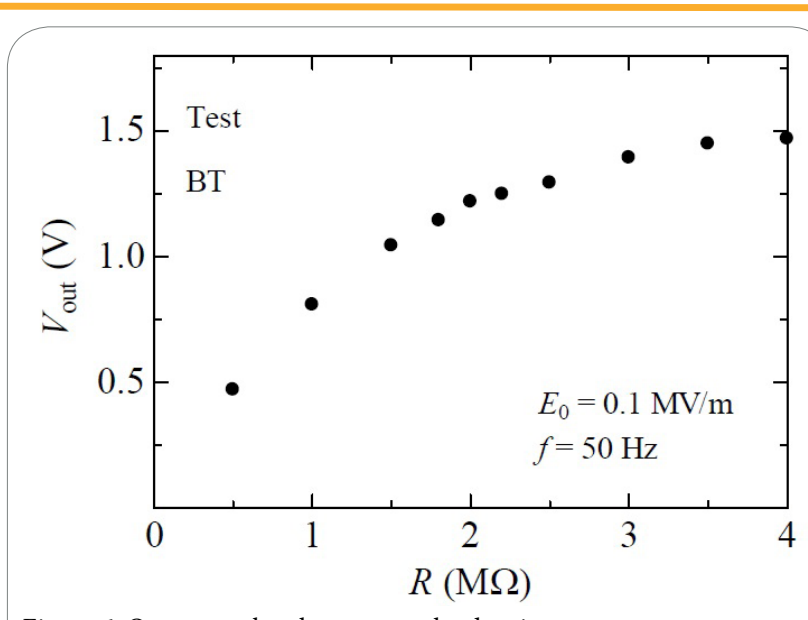

Figure 6: Output peak voltage versus load resistance.

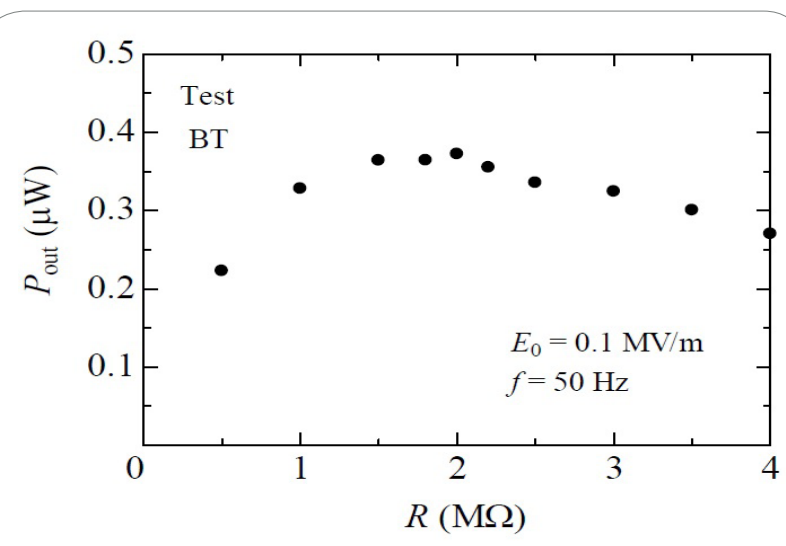

Figure 7:Output power versus load resistance.

\section{Conclusion}

This paper presents the results of numerical and experimental study in the BT unimorph cantilevers with sensing, grounding and driving electrodes under AC electric fields. On the basis of the study conducted, the following conclusions seem to be justified.

1. The tip deflection of the cantilever and the output peak voltage of the sensing electrode increase linearly without domain wall motion as the AC electric field amplitude increases.

2. The stress in the sensing part of BT unimorph cantilever is significantly higher than that in the driving part for the same AC electric fields.

3. The output power in the sensing electrode of BT unimorph cantilever under $0.1 \mathrm{MV} / \mathrm{m}$ can achieve about $0.4 \mu \mathrm{W}$ at $50 \mathrm{~Hz}$.

By knowing how the sensing and driving electrodes interact, we can design self-powering, self-sensing and self-controlling devices to achieve particular overall properties. Our present study offers a method for aiding the design of new BT-based multifunctional composites, and provides a basis for refining the real device design in order to reduce internal stresses and increase output voltage and output power.

\section{Competing Interests}

The authors declare that they have no competing interests.

\section{Author Contributions}

All the authors substantially contributed to the study conception and design as well as the acquisition and interpretation of the data and drafting the manuscript.

\section{Funding}

This work was supported by the Ministry of Education, Culture, Sports, Science and Technology of Japan under the Grant-in-Aid for Scientific Research (C).

\section{References}

1. Narita F, Shindo Y, Sato K (2011) Evaluation of electromechanical properties and field concentrations near electrodes in piezoelectric thick films for MEMS mirrors by simulations and tests. Comput Struct 89: 10771085.

2. Murasawa G, Nishioka A, Miyata K, Koda T, Cho H (2011) Electrically excited oscillation and crystalline structure of a nanoclay/poly(vinylidene fluoride) composite film. J Intell Mater Sys Struct 22: 2103-2112.

3. Shindo Y, Narita F, Sato K, Takeda T (2011) Nonlinear electromechanical fields and localized polarization switching of piezoelectric macrofiber composites. J Mech Mater Struct 6: 1089-1102.

4. Vatansever D, Hadimani RL, Shah T, Siores E (2011) An investigation of energy harvesting from renewable sources with PVDF and PZT. Smart Mater Struct 20: 055019.

5. Okayasu M, Sato D, Sato $Y$, Konno M, Shiraishi T (2012) A study of the effects of vibration on the electric power generation properties of lead zirconate titanate piezoelectric ceramic. Ceram International 38: 44454451.

6. Wang Y, Inman DJ (2013) Simultaneous energy harvesting and gust alleviation for a multifunctional composite wing spar using reduced energy control via piezoceramics. J Compos Mater 47: 125-146.

7. Saito Y, Takao H, Tani T, Nonoyama T, et al. (2004) Lead free piezoceramics. Nature 432: 84-87.

8. Lee HJ, Ural SO, Chen L, Uchino K, Zhang S (2012) High power characteristics of lead-free piezoelectric ceramics. J Am Ceram Soc 95: 3383-3386.

9. Wakatsuki N, Yokoyama H, Kudo S (1998) Piezoelectric actuator of $\mathrm{LiNbO}_{3}$ with an integrated displacement sensor. Jpn J Appl Phys 37: 2970-2973.

10. Jaffe H, Berlincourt DA (1965) Piezoelectric transducer material. Proceedings IEEE 53: 1372-1386.

11. Narita F, Shindo Y, Mikami M (2005) Analytical and experimental study of nonlinear bending response and domain wall motion in piezoelectric laminated actuators under ac electric fields. Acta Mater 53: 4523-4529. 